\title{
Detoxification of 1,2-dihydroxy- 4-allylbenzene, a major phenolic compound in Piper betle, through glucuronidation using S9 protein of rat liver (Sprague Dawley)
}

\author{
Erryana Martati* \\ Study Program of Food Science and Technology \\ Faculty of Agricultural Technology, Universitas Brawijaya \\ $\mathrm{Jl}$. Veteran Malang Indonesia
}

\begin{abstract}
1,2-dihydroxy- 4-allylbenzene (DHAB) is a major phenolic compound in Piper betle leaf and also a metabolite of safrole metabolism. Epidemiologic studies showed people who have betel quid chewing habit are related to the incidence of oral submucous fibrosis and/or tumor formation. The aims of this research was to study the detoxification through the glucuronidation of DHAB using S9 protein of male rat liver (Sprague Dawley) and a co-factor of uridin 5'-diphosphoglucuronide acid (UDPGA). The results showed that glucuronidation of DHAB using S9 protein of rat liver resulted two isomers of glucuronide metabolites due to the availibility of two active hydroxyl groups that one of them can bind glucuronide but not two of hydroxyl groups at the same time.
\end{abstract}

Keywords: 1,2-dihydroxy- 4-allylbenzene, safrole, glucuronidation, S9 protein rat liver, Piper betle

\section{Corresponding author:}

Erryana Martati

Study Program of Food Science and Technology

Faculty of Agricultural Technology, Universitas Brawijaya

J1. Veteran Malang Indonesia

Email:erryana_m@yahoo.com 


\section{INTRODUCTION}

1,2-dihydroxy-4-allylbenzene (DHAB) is a major phenolic compound in Piper betle leaf which is used for betel quid chewing for some Asian or Chinese and some other traditional medicines (Chung et al., 2008). It is also a major metabolite of safrole metabolism in rat and human in vitro experiment (Martati et al., 2011; Martati et al., 2012). The inflorescence of Piper betle used for betel quid chewing contains $9.74 \mathrm{mg} / \mathrm{g}$ wet weight of DHAB (Hwang et al., 1992). Chewing betel quid shows strong correlation to the incidence of oral cancer, leukoplakia and oral submucous fibrosis (IARC, 1985; Chang et al., 2001). Oral cancer cases in betel quid chewers are linked with alcohol drinker and tobacco smoker but It showed that betel quid chewing alone associated with oral cancer which was statistically significant (Ko et al., 1995). Safrole-DNA adducts were found in specimen of oral squamous cancer taken from Taiwanese patients who were tobacco betel quid chewers (Chang et al., 2001). The safrole-DNA adduct is formed through cytochrome P450 mediated formation of 1'hydroxysafrole which are then sulfonated resulting stable safrole-DNA adduct in vivo and in vitro experiments (Miller and Miller, 1981). Moreover, in vitro experiment with Chinese hamster ovary cells showed DHAB-induced oxidative DNA damage resulted 8-OH-dG (8-hydroxydeoxy-guanosine) formation which was responsible for the chromosome aberration, micronucleus formation and cytotoxicity (Lee-Chen et al., 1996).

Some studies showed that DHAB has bioactivity properties for both toxicological or health benefits aspects. DHAB has antioxidant, antinitrosation, antimutagenic and anticarcinogenic properties against various mutagens and carcinogens, inhibits the benzopyrene-DNA interactions activated by mouse and rat liver S9 protein (Amonkar et al., 1989). In contrast, DHAB may induce mutations in the Ames test, glutathione (GSH) depletion, reactive oxygen species (ROS) production, cell cycle arrest at higher concentration (Chang et al., 2002).

Another source of DHAB is from metabolism of safrole. Figure 1 shows metabolism of safrole results 1'-hydroxysafrole, 3'-hydroxysafrole, 2',3'-dihydroxysafrole dan 1,2-dihydroxy-4-allylbenzene (Martati et al., 2011; Martati et al., 2012). Safrole is a bioactive compound in some spices such as nutmeg, mace, cinnamon, star anise, ginger and black pepper (Periasamy et al ., 2016 ; Rocha et al., 2016) and a major compound in sassafras oil (Sasafras albidum). Intake of some food supplements containing those spices raise a health of concern (Al-Malahmeh et al., 2017; Berg et al., 2011). Pure safrole as flavoring agent has already banned by FDA (Food Drug Association) since December 1960 and by EFSA (European Food Safety Authority) food since 2008. Those prohibitions were taken because safrole is a genotoxic and carcinogenic compound in rodents assay. In rodents, safrole is metabolized in the liver through phase I metabolism mediated by cytochrome P450. Based on validated physiologically-based kinetic model of safrole metabolism for rat and human, the formation of DHAB was predicted 74.5 and $38.0 \%$ of the dose, respectively (Martati et al., 2011; Martati et al., 2012). The major detoxification pathway of 1'-hydroxysafrole resulted different pathway for rat and human which are glucuronidation and oxidation, respectively. DHAB undergoes conjugation reaction which could be glucuronidation, sulfation, and glutathione conjugations (Nakagawa et al., 2009). Therefore, it is necessary to study the detoxification of DHAB via glucuronidation in vitro. The aims of this research was to study the detoxification of glucuronidation of DHAB using S9 protein of rat liver and co-factor of uridin 5'-diphosphoglucuronide acid (UDPGA).

\section{MATERIALS AND METHODS Materials}

Materials: S9 protein from liver of rat (Sprague-Dawley) was obtained from BD Gentest (Worburn, USA). Uridine 5'-diphosphoglucuronide acid (UDPGA) was purchased from SigmaAldrich. Acetonitrile chromatography grade was obtained from Biosolve. Dimethyl sulfoxide (DMSO) 
was purchased from Acros Organic (New Jersey, USA). Tris (hydroxymethyl) aminomethane and alamethicin (from Trichoderma viride) were obtained from Roche Diagnostics Germany.

\section{Glucuronidation of DHAB}

Reaction of glucuronidation of DHAB was performed as previously described for 1'-hydroxy alkenylbenzenes (Punt et al., 2008;Al-Subeihi et al., 2011; Martati et al., 2011). The incubation mixtures were consisted of $10 \mathrm{mM}$ UDPGA, $0.2 \mathrm{mg}$ protein $\mathrm{S} 9 / \mathrm{mL}, 0.2 \mathrm{M}$ Tris- $\mathrm{HCl}(\mathrm{pH} 7.4)$ and 10 $\mathrm{mM} \mathrm{MgCl} 2$ (Table I) Pre-incubation with $0.025 \mathrm{mg} / \mathrm{mL}$ alamethicin for $15 \mathrm{~min}$ on ice was carried out to maximize glucuronidation enzyme activity (Fisher et al., 2000). After that, the mixture was incubated in a water bath at $37^{\circ} \mathrm{C}$ for $1 \mathrm{~min}$. Then, $1 \mathrm{uL}$ substrate of DHAB from a 200 time concentration stock solution in DMSO was added. Incubation was performed for $10 \mathrm{~min}$. The reaction was stopped by adding $50 \mu \mathrm{L}$ of cold acetonitrile. Sample was centrifuged at $16,000 \mathrm{~g}$ for $5 \mathrm{~min}$. Aliquots was stored at $-20^{\circ} \mathrm{C}$ prior HPLC analysis. Blank was made as the same for sample but without UDPGA added. Each treatment was repeated three times.

Table I. Composition materials for glucuronidation of DHAB

\begin{tabular}{ccc}
\hline Materials & Blank $(\mu \mathbf{L})$ & Sample $(\mu \mathbf{L})$ \\
\hline $0.2 \mathrm{M}$ Tris-HCl pH 7.4 and 10 & 196 & 146 \\
$\mathrm{mM} \mathrm{MgCl}$ & & \\
$10 \mathrm{mM} \mathrm{UDPGA}$ & 0 & 50 \\
S9 protein of rat liver & 2 & 2 \\
$0.025 \mathrm{mg} / \mathrm{mL}$ alamethicin & 1 & 1 \\
DHAB 50 $\mu \mathrm{M}$ & 1 & 1 \\
\hline
\end{tabular}

\section{HPLC Analysis}

Quantification of metabolites of glucuronidation reaction was performed on a HPLC equipped with photodiode array detector and column Alltima C18 $5 \mu \mathrm{m}, 150$ x $4.6 \mathrm{~mm}$ (Grace Alltech, Breda, The Netherlands). The gradient elutions were nanopure water containing $0.1 \%$ (v/v) acetic acid and acetonitrile. The flow rate was set at $1 \mathrm{~mL} / \mathrm{min}$. Gradient was programmed from $10 \%$ to $30 \%$ acetonitrile in $30 \mathrm{~min}$. After which, the acetonitrile was increased to $100 \%$ in $2 \mathrm{~min}$ and kept for $2 \mathrm{~min}$. After that, the acetonitrile was decreased to $10 \%$ in $2 \mathrm{~min}$ and kept for $10 \mathrm{~min}$. Chromatograms were compared between samples and blanks. The peaks appeared in the sample but not in blank were metabolite of glucuronides of DHAB. The absorbance of the peak was measured from 200 to $400 \mathrm{~nm}$ to obtain the UV spectra and confirm the identity of the peak.

\section{RESULTS AND DISCUSSION}

Glucuronidation is a glucuronic acid transfer from UDPGA to a large variety of aglycones (endo- and xenobiotics) catalyzed by UGTs (uridine diphosphate glucuronosyltransferases), a class of membrane bound enzymes of endoplasmic reticulum (Fisher et al., 2000). In metabolism of some alkenylbenzenes group, glucuronidaion is a major detoxification pathway (Punt et al., 2008; AlSubeihi et al., 2011; Martati et al., 2011; van den Berg et al., 2012). The addition of alamethicin in the incubation of glucuronidation reaction was performed to insert it in to the membranes and forming pores, therefore, it removes the latency of UGT activity (Fisher et al., 2000). Glucuronidation of DHAB with the cofactor of UDPGA resulted two metabolites (peak at time retention of 25.690 min dan $26.394 \mathrm{~min}$ ) as shown in Figure 2A and Figure 2B. A blank (without co-factor of UDPGA) shows no metabolite formed. This showed that glucuronidation of DHAB resulted two isomer of glucuronides metabolites. The UV spectra of the peaks shows that the two glucuronide metabolites have different UV spectra (Figure 2 (1) and Figure 2 (2)). Figure 2 (3) shows UV spectra of a substrate of DHAB. The peak area of the DHAB glucuronide appeared at $25.690 \mathrm{~min}$ and at 26.394 are $74.962 \pm$ 
9.765 and $200.563 \pm 27.687$, respectively. It shows that DHAB glucuronide peak appeared at 26.394 min is bigger than peak at 25.690 min. The concentration of each DHAB glucuronide was not quantified because un-available of the commercial standard compound of DHAB glucuronides.

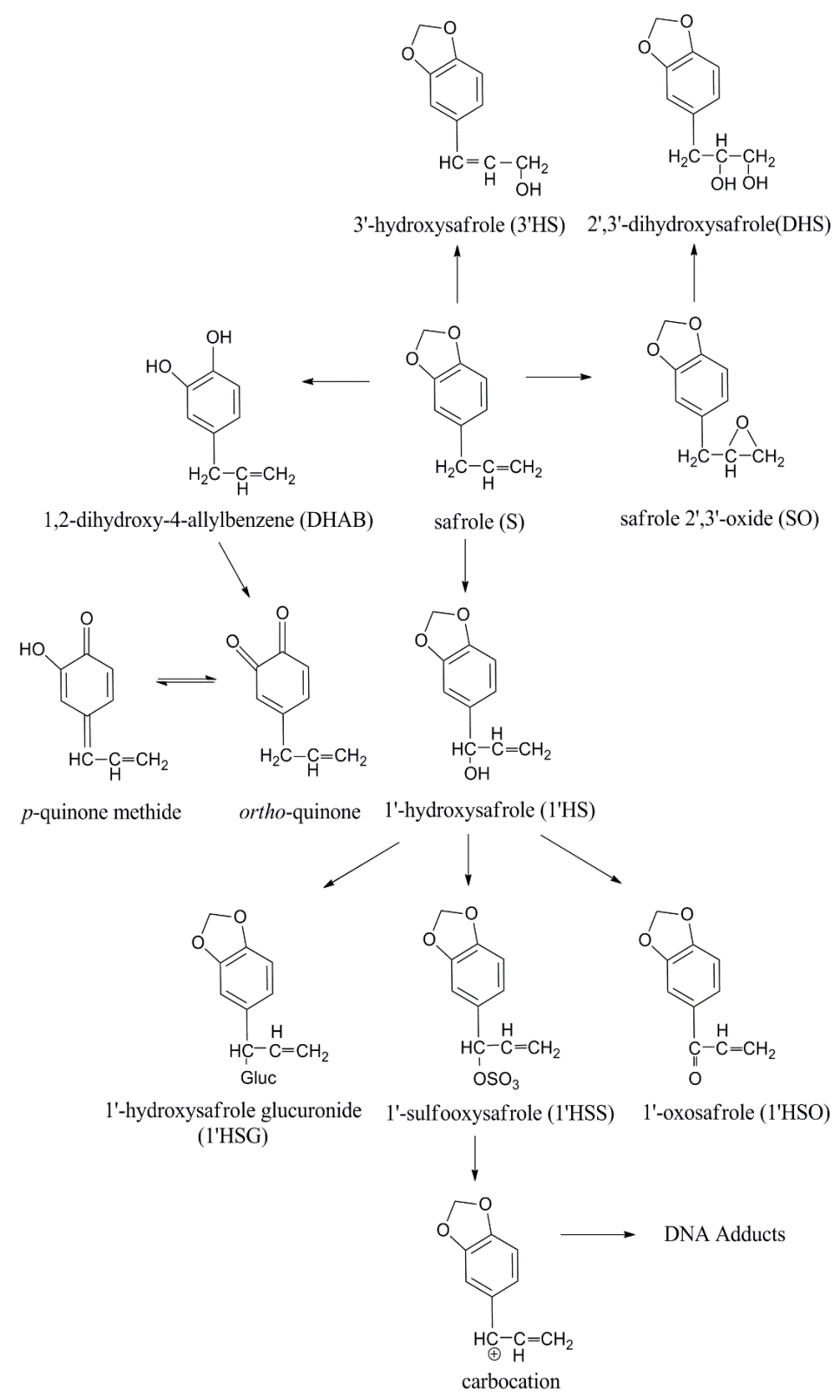

Figure 1. Metabolisme of safrole (Martati et al., 2011)

Experiment of Nakagawa et al., (2009) resulted that hydroxyl groups of DHAB are mostly converted to sulfat and/or glucuronides conjugates in the hepatocytes rat Male F344/Jcl exposed to DHAB (Nakagawa et al., 2009). It was found only one glucuronide of DHAB, although, there was one unknown peak next to the DHAB glucuronide showed in the chromatogram that was possibly another DHAB glucuronide (Nakagawa et al., 2009). The two hydroxyl groups in DHAB provide functional groups for conjugates but only single hydroxyl binds glucuronic acid (Figure 3). This is supported by (Nakagawa et al., 2009) that the diglucuronides of DHAB were not present as trace metabolites in 
incubation $\mathrm{DHAB}$ with rat hepatocyte suspensions. Glucuronidation plays an important role in detoxifying or inactivating some endogenous compounds and xenobiotics (Fisher et al., 2000). The glucuronide metabolites are readily excreted in the urine. In rat hepatocytes, DHAB showed more toxic in cells than the metabolites of glucuronides, sulfate dan GSH conjugates showing that those phase II reactions play important role in detoxification of DHAB (Nakagawa et al., 2009). In vitro mutagenicity test using Salmonella typhimurium TA97, TA98, TA100 and TA102 showed that exposure of cells with DHAB increased the number of those bacterial revertants indicated that DHAB were mutagenic compounds (Lee-Chen et al., 1996). In addition, exposure the cells with DHAB in the presence of S9 rat liver decreased the number of revertants. This indicated that metabolites of phase II reactions have less mutagenicity than those of DHAB (Lee-Chen et al., 1996).

A

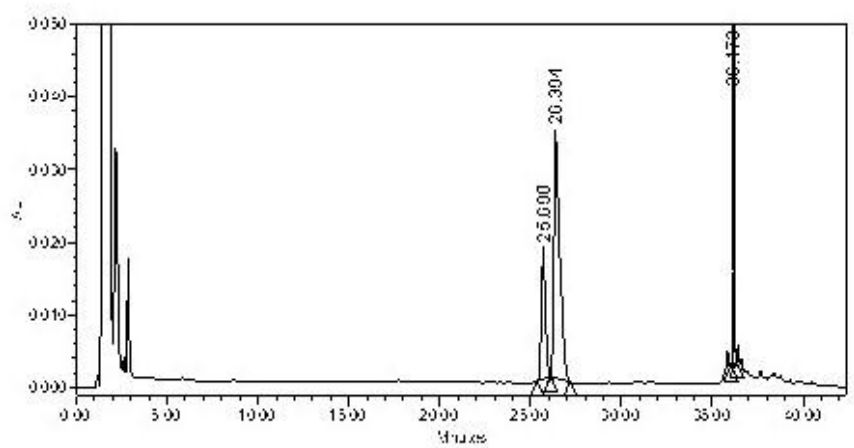

B

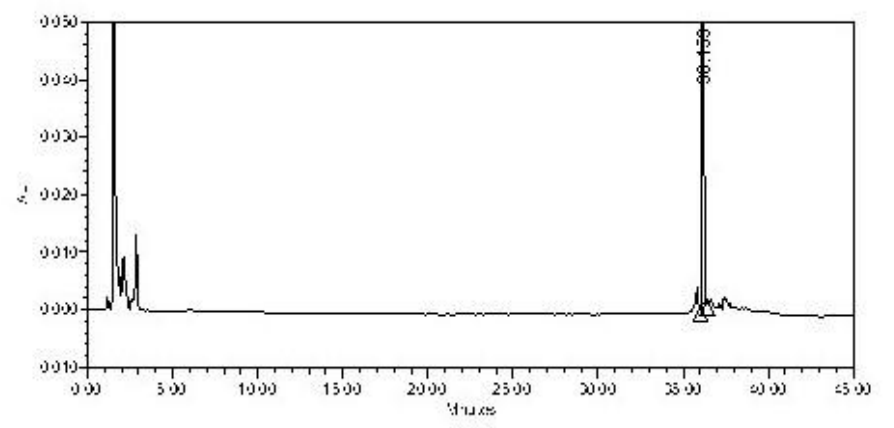

1

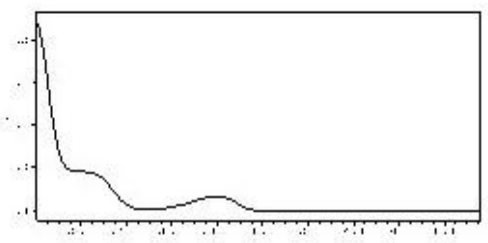

2

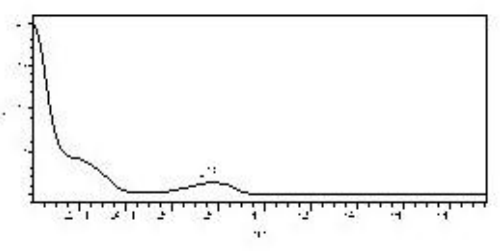

3

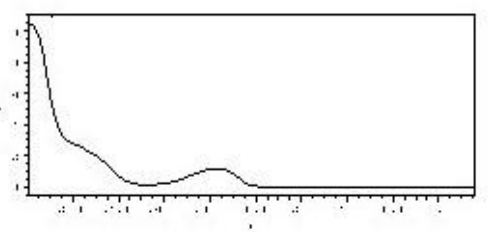

Figure 2. HPLC chromatogram of an incubation of DHAB $(0.25 \mu \mathrm{M})$ with male rat liver S9 homogenates in the presence of UDPGA as a cofactor (A) and without UDPGA (B). UV Spectrum of DHAB glucuronide peak at 25.690 min (1); DHAB glucuronide peak at $26.394 \mathrm{~min}$ (2); DHAB peak at $36.173 \mathrm{~min}(3)$ 


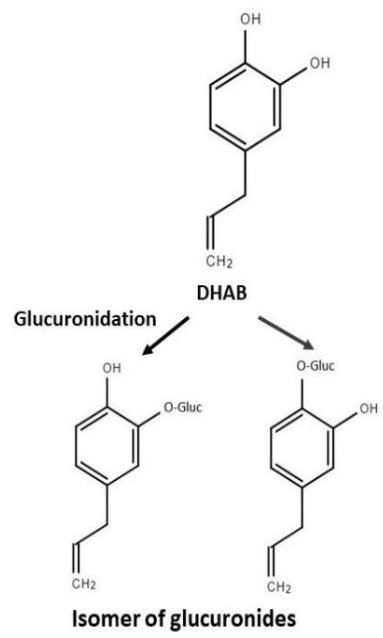

Figure 3. Proposed metabolites of glucuronidation of DHAB mediated rat liver S9 protein

\section{CONCLUSION}

Detoxificaton of DHAB through the glucuronidaton using rat liver S9 protein resulted two isomer metabolites of glucuronides due to the availibility of two active hydroxyl groups that one of them can bind glucuronide but not two of hydroxyl at the same time Those two glucuronides have unequal concentration of the metabolite.

\section{REFERENCES}

Al-Malahmeh A.J., Alajlouni A.M, Ning J, Wesseling S, Vervoort, J and Rietjens, I.M.C.M., 2017. Determination and risk assessment of naturally occurring genotoxic and carcinogenic alkenylbenzenes in nutmeg-based plant food supplements, Journal of Applied Toxicology, 37(10):1254-1264.

Al-Subeihi, A.A.A., Spenkelink, B., Rachmawati, N., Boersma, M.G., Punt, A., Vervoort, J., van Bladeren, P.J. and Rietjens, I.M.C.M., 2011. Physiologically based biokinetic model of bioactivation and detoxification of the alkenylbenzene methyleugenol in rat. Toxicology In Vitro, 25(1): 267-285.

Amonkar, A.J., Padma P.R. and Bhide, S.V., 1989. Protective effect of hydroxychavicol, a phenolic component of betel leaf, against the tobacco-specific carcinogens, Mutation Research, 210(2): 249-254.

Berg, S.J.P.L., Punt, A., Soffers, A.E.M.F., Vervoort, J., Ngeleja, S., Spenkelink, B. and Rietjens, I.M.C.M., 2012. Physiologically Based Kinetic Models for the Alkenylbenzene Elemicin in Rat and Human and Possible Implications for Risk Assessment, Chemical Research. Toxicology, 25(11): 2352-67.

Berg S. J. P. L., Restani, P., Boersma M. G., Delmulle L. and Rietjens I. M. C. M., 2011. Levels of Genotoxic and Carcinogenic Compounds in Plant Food Supplements and Associated Risk Assessment, Food and Nutrition Sciences, 2(9): 989-1010.

Chang, M. C., Ho, Y. S., Lee, P. H., Chan, C. P., Lee, J. J., Hahn, L. J., Wang, Y. J. and Jeng, J. H., 2001. Areca Nut Extract And Arecoline Induced The Cell Cycle Arrest but Not Apoptosis of Cultured Oral KB Epithelial Cells: Association of Glutathione, Reactive Oxygen Species and Mitochondrial Membrane Potential, Carcinogenesis, 22(9): 1527-1535. 
Chang M.C., Uang B.J, Wu H.L., Lee J.J, Hahn L.J. and Jeng J.H., 2002. Inducing the cell cycle arrest and apoptosis of oral KB carcinoma cells by hydroxychavicol: roles of glutathione and reactive oxygen species, British Journal Pharmacology,135(3): 619-30.

Chung, Y.T., Chen, C.L., Wu, C,C.,Chan, S.A.,Chi, C.W. and Liu, T.Y., 2008. Safrole-DNA adduct in hepatocellular carcinoma associated with betel quid chewing. Toxicology Letter, 183 (1-3), 21 27.

Fisher, M.B., Campanale, K., Ackermann, B.L., Van den Branden, M. and Wrighton, S.A., 2000. In vitro glucuronidation using human liver microsomes and the pore-forming peptide alamethicin, Drug Metabolism and Disposition, 28(5): 560-566.

Hwang, L.S., Wang, C.K., Sheu, M.J. and Kao, L.S., 1992. Phenolic Compounds of Piper betle Flower as Flavoring and Neuronal Activity Modulating Agents, In: Ho, C.T., Chang, Y.L., Huang, M.T. (Eds.), Phenolic Compounds in Food and Their Effects on Health I. American Chemical Society, Washington DC.

IARC (International Agency For Research on Cancer), 1985. Monograph on the Evaluation of the Carcinogenic Risk of Chemical to Humans: Tobacco Habits Other than Smoking;Betel-Quid and Areca-Nut Chewing; and Some Related Nitrosamines, Vol.37, IARC, Lyon.

Ko, Y.C., Huang, Y.L, Lee, C.H, Chen, M.J, Lin, L.M. and Tsai, C.C., 1995. Betel quid chewing, cigarette smoking and alcohol consumption related to oral cancer in Taiwan, Journal of Oral Pathology and Medicine, 24: 450-453.

Lee-Chen,S.F., Chen, C.L., Ho,L.Y., Hsu, P.C., Chang, J.T., Sun, C.M., Chi C.W. and Liu, T.Y., 1996. Role of oxidative DNA damage in hydroxychavicol-induced genotoxicity, Mutagenesis 11(5):519-523.

Martati, E., Boersma, M.G., Spenkelink, A., Khadka, D.B., Punt, A., Vervoort, J., van Bladeren, P.J. and Rietjens, I.M.C.M., 2011. Physiologically Based Biokinetic (PBBK) model for safrole bioactivation and detoxification in rats, Chemical Research in Toxicology, 24(6): 818-834.

Martati, E., Boersma, M.G., Spenkelink, A., Khadka, D.B., van Bladeren, P.J., Rietjens, I.M.C.M. and Punt, A., 2012. Physiologically Based Biokinetic (PBBK) Modeling of Safrole Bioactivation and Detoxification in Humans as Compared With Rats, Toxicological Science, 128(2): 301316.

Miller, E.C and Miller J,A., 1981. Searches for ultimate chemical carcinogens and their reactions with cellular macromolecules, Cancer, 47(10): 2327-2345.

Nakagawa, Y., Suzuki, T., Nakajima, K., Ishii, H. and Ogata, A., 2009, Biotransformation and cytotoxic effects of hydroxychavicol, an intermediate of safrole metabolism, in isolated rat hepatocytes, Chemical Biological Interaction, 180(1): 89-97.

Periasamy, G., Karim, S., Gibrelibanos, M., Gebremedhin, G. and Gilani, A.H., 2016. Nutmeg (Myristica fragrans Houtt.) Oils. In Preedy, V.R., Essential oil in Food Preservation, Flavor and Safety, Elsevier, London UK, 607-613.

Punt, A., Freidig, A.P., Delatour, T., Scholz, G., Boersma, M.G., Schilter, B., van Bladeren, P.J. and Rietjens, I.M.C.M., 2008. A physiologically based biokinetic (PBBK) model for estragole bioactivation and detoxification in rat, Toxicology and Applied Pharmacology, 231(2): 248259.

Rocha, L, Armando, L, and Tietbohl, C., 2016. Staranise (Illicium verum Hook) Oil. In Preedy, V.R., Essential oil in Food Preservation, Flavor and Safety, Academic Press, London UK, 751-756. 
